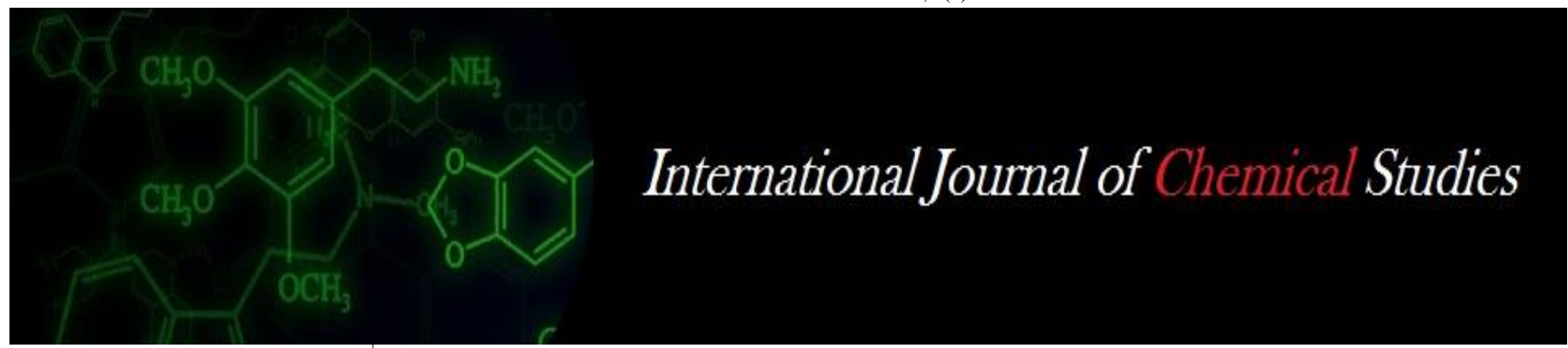

P-ISSN: 2349-8528

E-ISSN: 2321-4902

www.chemijournal.com

IJCS 2020; 8(4): 236-238

(C) 2020 IJCS

Received: 04-05-2020

Accepted: 07-06-2020

\section{Deepa KB}

Department of Sericulture, UAS GKVK, Bangaluru, Karnataka, India

\section{Fathima Sadatulla}

Department of Sericulture, UAS GKVK, Bangaluru, Karnataka, India

\section{Vishaka GV}

Department of Sericulture, UAS GKVK, Bangaluru, Karnataka, India

Divyashree HJ

Department of Sericulture, UAS GKVK, Bangaluru, Karnataka, India

Corresponding Author:

Deepa KB

Department of Sericulture, UAS

GKVK, Bangaluru, Karnataka,

India

\section{Effect of amino acid formulation as foliar spray on growth and yield of $V-1$ mulberry variety}

\author{
Deepa KB, Fathima Sadatulla, Vishaka GV, Divyashree HJ and Nithya \\ BN
}

DOI: https://doi.org/10.22271/chemi.2020.v8.i4d.9696

\begin{abstract}
A study on "Effect of Amino acid formulation as foliar spray on growth and yield of V-1 mulberry variety was conducted by utilizing the established V-1 mulberry garden at department of Sericulture, UAS, G.K.V.K., Bengaluru during 2016-17. Spraying of 3.5\% amino+ spray on 25th and 35th day after pruning recorded maximum plant height $(166.85 \mathrm{~cm})$, longest shoot height $(122.67 \mathrm{~cm})$, more number of leaves per plant (298.49), highest number of shoots per plant (15.76), less internodal distance $(5.88 \mathrm{~cm})$ maximum leaf yield per plant (511.08 g/plant). The details are discussed.
\end{abstract}

Keywords: Foliar spray, amino acid formulation, mulberry growth parameters

\section{Introduction}

Mulberry (Morus sp.) is a perennial crop. Mulberry, the sole food plant of silkworm, Bombyx mori L. plays a vital role in the growth and development of silkworm and in turn the silk production. Leaf quality and quantity not only influence the silkworm growth and development, but also the cocoon production and quality of raw silk. Nearly 70 per cent of silk protein produced by silkworm is derived directly from proteins of mulberry leaves. Among several factors that are known to contribute for successful silkworm crop production mulberry leaf alone accounts for $(38.20 \%)$, climate $(37.0 \%)$, rearing techniques $(9.3 \%)$, silkworm breed $(4.2 \%)$, silkworm seed $(3.1 \%)$ and other factors (8.2\%), (Miyashita, 1986) ${ }^{[4]}$. mulberry belonging to the family Moraceae and is the sole food of silkworm Bombyx mori L. Foliar feeding is a way of supplementing the nutrients quickly and specifically and also for stimulation of plant metabolism. Foliar fertilization has been used as a means of supplying supplemental doses of major and minor nutrients, plant hormones, stimulants and other beneficial substances. The plant nutrients which are absorbed through roots can also be absorbed with equal efficacy through foliage (Del, 1971) ${ }^{[1]}$ and often several times more efficiently than from soil treatments (Sastry and Appajirao, 1958) ${ }^{[8]}$. Foliar sprays minimize wastage and the quantity to be sprayed is fairly a fraction of what be required for soil application During the last two decades studies on foliar nutrition has received considerable crop, leaf quality alone contributes 38.30 per cent (Juyal et al., 2003) ${ }^{[2]}$

\section{Materials and Methods}

The field experiment was conducted at the Department of Sericulture, G.K.V.K., UAS, and Bengaluru during 2016-17. The experiment was laid out in Randomized Complete Block Design with 10 treatments and three replications. The experiment consisted of foliar application of amino acids $\left(\mathrm{amino}^{+}\right)$in different concentration at different intervals. The treatment were as follows

T1 -Absolute control (No POP)

$\mathrm{T} 2-\mathrm{POP}+$ Water spray

$\mathrm{T} 3-\mathrm{POP}+2.0 \%$ amino $^{+}$at $25^{\text {th }} \mathrm{DAP}$ and $35^{\text {th }} \mathrm{DAP}$

$\mathrm{T} 4-\mathrm{POP}+2.5 \%$ amino $^{+}$at $25^{\text {th }} \mathrm{DAP}$ and $35^{\text {th }} \mathrm{DAP}$

T5 -POP $+3.0 \%$ amino $^{+}$at $25^{\text {th }}$ DAP and $35^{\text {th }}$ DAP

T6- POP $+3.5 \%$ amino $^{+}$at $25^{\text {th }} \mathrm{DAP}$ and $35^{\text {th }} \mathrm{DAP}$

$\mathrm{T} 7-\mathrm{POP}+2.0 \%$ amino $^{+}$at $25^{\text {th }} \mathrm{DAP}$ and $35^{\text {th }} \mathrm{DAP}$ 
$\mathrm{T} 8-\mathrm{POP}+2.5 \%$ amino $^{+}$at $25^{\text {th }} \mathrm{DAP}$ and $35^{\text {th }} \mathrm{DAP}$

T9- POP $+3.0 \%$ amino $^{+}$at $25^{\text {th }}$ DAP and $35^{\text {th }}$ DAP

T10- POP $+3.5 \%$ amino ${ }^{+}$at $25^{\text {th }} \mathrm{DAP}$ and $35^{\text {th }} \mathrm{DAP}$

*DAP- Days after pruning

* POP-package of practice recommended dose of NPK at the rate of $350: 140: 140 \mathrm{~kg} / \mathrm{ha} / \mathrm{year}$ and FYM at the rate of 20 MT/ha/year was applied.

Amino acid formulation Amino ${ }^{+}$used as a foliar spray applied at different concentration at different intervals. Amino ${ }^{+}$is a liquid organic plant growth promoter containing 16 free bio available and biodegradable amino acids, it is compatible with all commonly used agro chemicals. Amino ${ }^{+}$is neither toxic nor harmful and non-phototoxic. It is suitable for all agroclimatic zones. It contains total dissolved solids 30-33\%, hydrolysed protein $9-11 \%$, hydrolyzed carbohydrates $6-7 \%$, amino nitrogen $3.5-4 \%$. Amino acids which increase the endogenous plant hormones or inhibit some endogenous hormones e.g., auxins, cytokinin setc., inhibit the negative hormone like abscisic acid, ethylene etc.

\section{Results and Discussion}

Application of chemical fertilizers directly to the soil affects the soil ecosystem. Under these circumstances it is more effective to go for supplying nutrients through foliar spray. Foliar sprays are less concentrated than the chemical fertilizers applied to the soil. Mulberry has the capacity to absorb nutrients much more effectively and quicker through leaf, owing to comparatively larger leaf area when supplied through foliar spray. Amino acid foliar spray to mulberry leaves has helped in improving the nutrient content of mulberry, in turn to provide the required nutrients for better growth of the silkworm leading to improved qualitative and quantitative cocoon production. This work is the first of its kind because there is no available literature pertaining to the use of amino acid foliar spray. This being the case, the current topic is discussed in the light of related findings under the following headings

\section{Growth Parameters of V-1mulberry}

Application of different concentrations of amino+ foliar spray showed significant increase in growth parameters of $\mathrm{V}-1$ mulberry (Table 1 to 2 ). The maximum plant height (166.85 $\mathrm{cm})$, number of shoots per plant (15.76) and number of leaves per plant (298.49) were significantly higher in V-1mulberry raised with $3.5 \%$ amino+ sprayed on 25 th and 35 th day after pruning. However, lowest plant height, number of shots per plant and number of leaves per plant $(135.95 \mathrm{~cm}, 11.18$, 202.67 respectively) was recorded in absolute control. The profound increase in plant height, number of shoots per plant and number of leaves per plant was clearly due to treatment (foliar spray of amino ${ }^{+}$in different concentrations on different days after pruning). When amino ${ }^{+}$was sprayed on plants the mulberry leaves quickly absorbed the nutrients into their system, which has apparently stimulated vigorous growth of the mulberry plants there by resulting in increased plant height, number of shots and number of leaves. This may be due to the fact that amino $^{+}$contains mainly the growth promoting nutrient composition(total dissolved solids 30$33 \%$, hydrolysed protein $9-11 \%$, hydrolysed carbohydrates $6-$ $7 \%$, amino nitrogen $3.5-4 \%$.). Though there is a variation in treated plant height, number of shoots per plant and number of leaves per plant, which can be attributed to the variation in concentration used. Similar results were observed by Vivek uppar and Rayar (2014) [11] who evaluated organically produced foliar sprays viz., vermiwash, biodigester and panchagavya sprayed on M-5 mulberry. Among the organic foliar sprays used at 1, 3 and 5 per cent, Vermiwash spray at 5 per cent on 15th and 30th days after pruning significantly increased the plant height ( 87.42 and $129.16 \mathrm{~cm})$, shoot length (86.14 and $127.15 \mathrm{~cm})$, number of leaves (16.4 and 22.19) on 45th and 60th days after pruning, respectively. Further, the growth parameters in the present study showed almost the similar trend revealed, foliar spray of Vermiwash @ 200 ppm twice on V-1 mulberry at 25 and 35 days after pruning significantly improved the leaf yield $(72600 \mathrm{~kg} / \mathrm{ha} / \mathrm{yr})$ over unsprayed mulberry (45735 kg/ha/yr), besides significant increase in plant height $(199.50 \mathrm{~cm})$, shoot length $(189 \mathrm{~cm})$, number of branches per plant (13.00) and number of leaves per plant (155) (Venkataramana et al., 2009) ${ }^{[10]}$. Prasanna Kumar et al. (2001) ${ }^{[6]}$ studied the effect of 'Green leaf' on mulberry, 'Green leaf' was sprayed at $5 \mathrm{ml} / \mathrm{lit}$ on M-5 and V1 after pruning. Number of shoots per plant, shoot length and number of leaves per plant was significantly more in both $\mathrm{M}$ 5 and V-1 mulberry due to 'Green leaf' foliar spray. The pooled data of two crops revealed significantly less internodal distance $(5.88 \mathrm{~cm})$, height of longest shoot $(122.67 \mathrm{~cm})$ recorded on 60th day after pruning in V-1 mulberry raised by foliar spray of $3.5 \%$ amino $^{+}$on 25 th and 35th day after pruning (T6) respectively. However, the maximum internodal distance $(6.89 \mathrm{~cm})$, lower longer shoot height $(74.20 \mathrm{~cm})$ is noticed in absolute control (T1). The reduction in the internodal distance in mulberry apparently is due to the foliar application of amino $^{+}$to the plants which has resulted in increased number of shoots which has resulted in less intermodal distance. Similar trend was observed by spraying of 'Daman Penshibao' micronutrient foliar spray at $0.5 \mathrm{ml} / 10$ lit of water on M-5 mulberry which significantly showed higher shoot height and reduced internodal distance of 108.25 $\mathrm{cm}$ and 5.75 respectively. (Jyothi et al., 2000) ${ }^{[3]}$.

\section{Leaf Yield Parameters}

Notable variation was observed with respect to leaf yield per plant and leaf yield per hectare of mulberry due to different concentrations of amino ${ }^{+}$foliar spray when applied to $\mathrm{V}-1$ mulberry (Table 3). Among the different treatments, maximum leaf yield per plant $(511.08 \mathrm{~g} /$ plant $)$ was recorded in T6 which has received $3.5 \%$ amino $^{+}$spray on 25 th day and 35 th day after pruning. The lowest fresh leaf yield of $387.63 \mathrm{~g} /$ plant was recorded in $\mathrm{T} 1$.

The increased leaf yield can be attributed to more number of shoots, increased plant height and more number of leaves per plant. The positive influence of foliar spray on leaf yield in terms of fresh weight can also be attributed to the conjunctive application of amino $^{+}$foliar spray. The lowest leaf yield has been recorded in untreated control plot. Narahari Rao et al. (2001a) [5] studied the response of M-5 mulberry to the application of commercial foliar spray. Four commercial foliar sprays viz., Seriboost (2.5 ml/lit), Agroboom (2.0 $\mathrm{ml} / \mathrm{lit})$, Booster $(5.0 \mathrm{ml} / \mathrm{lit})$ and Harith $(2.5 \mathrm{ml} / \mathrm{lit})$ were sprayed twice at 7 days interval after foliage development. Seriboost foliar spray has increased the leaf yield $(6760.5$ $\mathrm{kg} / \mathrm{ha} / \mathrm{crop}$ ), number of leaves/plant (131) over control (5691.50 and 126, respectively). Foliar application of aqueous solution of GA3 (10 ppm) on ten mulberry varieties gave positive response in terms of leaf yield. Leaf yield was more in S-54 (797.4 g/plant), S-799 (537.10 g/plant), S-36 (611.80 g/plant), K-2 (625.90 g/plant) and Mysore local (458.90 $\mathrm{g} /$ plant) as compared to control (416.70 g/plant) (Singhvi et al., 2003). The results of the present investigations agree with the findings of Rajegowda and Raju (2011) ${ }^{[7]}$ who reported 
that foliar spray of micronutrients composition (Boron $0.50 \%$, Molybdenum $0.01 \%$, Copper $0.20 \%$, Iron $2.0 \%$, Zinc $2.5 \%$ and Manganese 1.0\%) @ $2.5 \mathrm{ml} / \mathrm{lit}$ of water, one, twice and thrice on 16, 23 and 30 days after pruning on $\mathrm{V}-1$ mulberry significantly increased shoot height, number of leaves, leaf yield per plant and leaf yield per/ha during three successive crops.

Table 2: Growth parameters of V-1 mulberry as influenced by foliar application amino acid formulation on 60th day after pruning

\begin{tabular}{|c|c|c|c|}
\hline Treatments & Number of leaves/plant & Number of shoots/plant & Internodal distance (cm) \\
\hline $\mathrm{T}_{1}$-(No RDF) absolute Control & 202.67 & 11.18 & 6.89 \\
\hline $\mathrm{T}_{2}-\mathrm{RDF}+$ Water spray & 218.16 & 12.35 & 6.74 \\
\hline $\mathrm{T}_{3}-\mathrm{RDF}+2.0 \%$ amino $^{+}$at $25^{\text {th }} \mathrm{DAP}$ and $35^{\text {th }} \mathrm{DAP}$ & 239.35 & 14.45 & 6.44 \\
\hline $\mathrm{T}_{4}-\mathrm{RDF}+2.5 \%$ amino $^{+}$at $25^{\text {th }} \mathrm{DAP}$ and $35^{\text {th }} \mathrm{DAP}$ & 252.32 & 15.09 & 6.17 \\
\hline $\mathrm{T}_{5}-\mathrm{RDF}+3.0 \%$ amino $^{+}$at $25^{\text {th }} \mathrm{DAP}$ and $35^{\text {th }} \mathrm{DAP}$ & 277.67 & 15.50 & 6.08 \\
\hline $\mathrm{T}_{6}-\mathrm{RDF}+3.5 \%$ amino $^{+}$at $25^{\text {th }} \mathrm{DAP}$ and $35^{\text {th }} \mathrm{DAP}$ & 298.49 & 15.76 & 5.88 \\
\hline $\mathrm{T}_{7}-\mathrm{RDF}+2.0 \%$ amino $^{+}$at $30^{\text {th }} \mathrm{DAP}$ and $40^{\text {th }} \mathrm{DAP}$ & 232.67 & 14.39 & 6.55 \\
\hline T8-RDF $+2.5 \%$ amino $^{+}$at $30^{\text {th }}$ DAP and $40^{\text {th }}$ DAP & 244.93 & 14.56 & 6.44 \\
\hline $\mathrm{T}_{9}-\mathrm{RDF}+3.0 \%$ amino $^{+}$at $30^{\text {th }} \mathrm{DAP}$ and $40^{\text {th }} \mathrm{DAP}$ & 272.29 & 14.85 & 6.27 \\
\hline $\mathrm{T}_{10}-\mathrm{RDF}+3.5 \%$ amino ${ }^{+}$at $30^{\text {th }} \mathrm{DAP}$ and $40^{\text {th }} \mathrm{DAP}$ & 274.73 & 15.37 & 6.10 \\
\hline F-Test & $*$ & $*$ & $*$ \\
\hline S.Em \pm & 3.072 & 0.38 & 0.17 \\
\hline CD@5\% & 9.129 & 1.11 & 0.51 \\
\hline
\end{tabular}

DAP- Days after pruning * -Significant

POP=NPK @ 350:140:140 kg/ ha/ year+FYM@20 MT/ha/year

Table 3: Leaf yield of V-1 mulberry as influenced by foliar application of amino acid formulation on 60th day after pruning

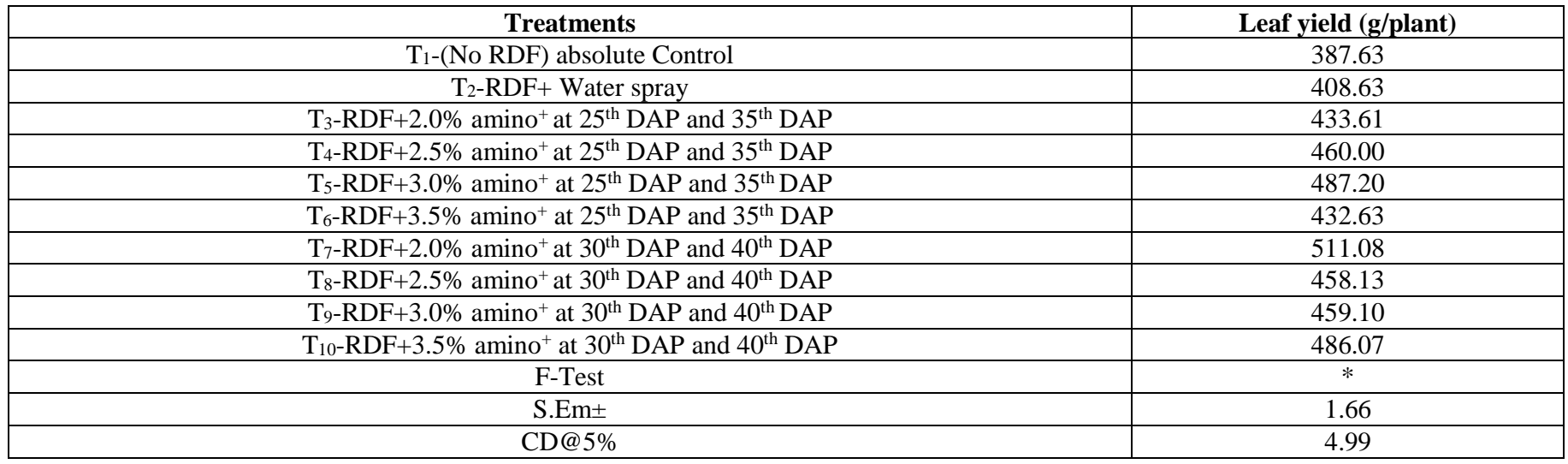

\section{References}

1. Del R. A review of foliar fertilization of crops in India. Fertil. News. 1971; 16(12):77-78

2. Juyal AC, Singh BD, Rajat M, Ramakant M, Gonashyam M. S-146-A suitable mulberry genotype for northwestern India. Indian Silk. 2003; 41:9-10.

3. Jyothi BL, Govindan R, Shanthakumar K. Performance of silkworm, Bombyx mori on mulberry raised by foliar application of Daman penshibao. Paper presented In: Nation Conf. Seric. Res. Dev, CSR\&TI, Mysore, 2000, 67.

4. Miyashita Y. A report on mulberry cultivation and training methods suitable to bivoltine rearing in Karnataka, 1986, 1-7.

5. NaraharI Rao BV, Bongale UD, Chaluvachari, Krishna M. Response of mulberry to the application of commercial foliar sprays. Proc. Nation. Sem. Mulb. Seri. Res. India, Karnataka State Sericulture research and development institute, Bangalore, 2001a, 233-236.

6. Prasanna Kumar GS, Lokesh G, Ananthanarayana SR. Field performance of silkworm hybrids raised on mulberry with foliar application. Proc. Nation. Sem. Mulb. Seri. Res. India. Karnataka State Seri. Res. Dev. Inst. Bangalore, 2001, 448-454.

7. Rajegowda, Raju M. Effect of micronutrients foliar spray on mulberry growth, silk production and cost benefit. J Ecobiol. 2011; 28(1):49-53.
8. Sastry VVK, Appaji Rao B. Foliar application of nutrients. Andhra Agric. J. 1958; 5(2):294-301.

9. Singhvi NR, Kodandaramaiah J, Mala Rajan V, Singh GB, Himantharaj MT. Foliar application of gibberllic acid to improve mulberry leaf yield, quality and commercial characteristics of silkworms.Paper presented In: Nation. Sem. Strat. Seri. Res. Dev. CSR \& TI, Mysore, 2003, 54.

10. Venkataramana P, Narasimhamurth Y, Krishna Rao B, Kamble CK. Efficacy of foliar sprays of vermiwash and cowdung wash on biochemical and yield attributes and yield of mulberry (Morus Alba L.). Karnataka J Agril. Sci. 2009; 22(4):921-923.

11. Vivek Uppar, Rayar SG. Bio-efficacy of organic foliar sprays on mulberry and cocoon production. J ENT. Res. 2014; 38(1):35-39. 